\title{
Agricultural Sustainability and Environmental Change at Ancient Gordion. By John M. Marston. 2017. University of Pennsylvania Museum Press, Philadelphia. 224 pp.
}

\author{
Erica Rowan ${ }^{1 *}$ \\ ${ }^{1}$ Department of Classics, Royal Holloway, University of London, Egham, UK. \\ *erica.rowan@rhul.ac.uk
}

Received August 29, 2018

OPEN ठACCESS

Accepted October 5, 2018

DOI 10.14237/ebl.9.2.2018.1391

Copyright (c) 2018 by the author(s) licensee Society of Ethnobiology. This is an open-access article distributed under the terms of the Creative Commons Attribution-NonCommercial 4.0 International Public License (https://creativecommons.org/licenses/by-nc/4.0), which permits non-commercial use, distribution, and reproduction in any medium, provided the original author and source are credited.

The ancient site of Gordion, located in central Anatolia (Turkey), is composed of a citadel mound, a lower town, an outer town, and multiple tumuli or burial mounds. Although population density varied over the centuries, the site was occupied consistently from the early Bronze Age until the late Roman period or roughly $3000 \mathrm{BC}$ until the fifth century AD. After a period of almost total abandonment, the urban center and surrounding region were resettled during the thirteenth to fourteenth centuries.

John Marston is an archaeobotanist who has studied the plant material from Gordion for over a decade. While both he and fellow archaeobotanist Naomi Miller (Marston 2010; Marston and Miller 2014) have published several articles on various archaeobotanical and environmental aspects of the site, this book combines both pre-existing and new data sets to present and analyze all the archaeobotanical and wood charcoal material collected from the 1985-2005 excavation seasons. The volume consists of six chapters, two appendices, and two extensive online appendices that provide the reader with all the raw data, displayed on a sample by sample basis.

The volume presents one of the largest and chronologically most extensive data sets from Turkey and is a rare example of an archaeobotany monograph. The volume seeks to answer two questions; namely which agricultural strategies were employed at Gordion and what was the reciprocal relationship between environmental change and human decision making with regards to land-use practices? These are pertinent questions and the volume promises to make use of the data rather than simply present it, as unfortunately remains the case with many archaeobotany publications. In the end the volume does answer these questions, but it is on a rather broad level and at times the discussion gets tangled up in an overuse of theory and repetitious writing.

The first chapter introduces the aims and methodological approach of the volume and presents crucial information on the site, its chronology, and its lengthy excavation history. The second chapter is dedicated to an overview and explanation of the two theoretical models that will be employed and integrated throughout the remainder of the text: behavioral ecology and resilience thinking. Behavioral ecology, when used in archaeological contexts, relates to foraging theory, and in the specific context of the monograph, to the production of food through agriculture and animal husbandry. Resilience thinking looks at the relationship between ecological systems and social systems, in other words the reciprocal relationships between humans and environments. The description of each theoretical framework is simultaneously detailed and vague in that the history of the theories and their current functions are thoroughly presented, but almost no examples or hypotheticals are employed to demonstrate how they would work in an archaeological context. Similarly, it would have been helpful to see these theories integrated with past and current archaeological schools of thought since Marston often criss-crosses the boundaries between processual and postprocessual archaeology. 
The third chapter combines geomorphological, phytogeographical, meteorological, and paleoclimate proxy data to create a detailed reconstruction of past climate and landscape around Gordion for the length of its occupation history. While extremely thorough in terms of research and data collection, it is a long chapter that would have benefited from a more succinct presentation of the material.

The following chapter begins with a description of the methodological approach used to collect and identify the site's wood charcoal before moving on to a discussion of local vegetation and then finally presenting the results. Focussing on diachronic changes in wood use, Marston is able to demonstrate that extensive use of juniper during the Late Bronze Age results in changes to the local forest structure and subsequently pine and oak become the most common wood types in all later periods. Depositional and spatial analysis of the charcoal also reveals juniper and pine to be the preferred construction materials for large buildings while oak tended to be used for smaller domestic structures. Local wood types that could be collected with the least amount of effort were used for fuel, apparently regardless of activity type (e.g., hearth, kiln, and religious offering). For reasons that remain unclear, the author chose only to look at hand-picked charcoal and did not include large fragments collected from flotation. The absence of the flotation charcoal seems to have limited the ability to distinguish fuel selection practices as sampling for flotation often took place in areas with obvious patches of charring, thereby reducing the volume of charcoal available for analysis. Similarly, a discussion of the burning characteristics and qualities of each wood type was missing as were any references to Robyn Veal's $(2009,2012)$ similar and extensive work on Pompeii.

The fifth chapter moves away from charcoal to look at the archaeobotanical remains. Following a thorough discussion of diet, the chapter then turns to an assessment of agricultural risk management strategies such as crop diversification and the longterm impact of agriculture and grazing on the surrounding environment. Making excellent use of a combination of geology and weed seed data, Marston is able to show that more intensive agricultural practices, such as irrigation, are introduced during the Middle and Late Phrygian periods due to rapid population increase. The Roman period is characterized by intensive bread wheat production and extensive animal grazing that led to overgrazing and increased alluviation of the local Sakarya river. The final chapter succinctly summarizes all the previous chapters and differentiates between environmental and cultural drivers of change. It is in this final chapter that the book really demonstrates its value to both ethnobiology and archaeology as the complicated and reciprocal relationships between humans, environments, culture, and climate becomes readily apparent.

That I am an archaeologist reviewing this monograph in an ethnobiology journal highlights the interdisciplinarity of the book and the current direction of archaeobotanical research. The integration of behavioral ecology and resilience thinking is one of the more novel aspects of the volume. However, its core strength lies in the full presentation of both the charcoal and archaeobotanical material and on Marston's ability to interweave a growing body of paleoclimate data with his own findings to paint a clear picture of human and environmental change at Gordion over roughly 3000 years. The volume nevertheless suffers from some drawbacks. Firstly, the intended audience of the book is not clear and that had a significant impact on the writing style and presentation. At times there is far too much background information for the archaeobotanist or archaeologist familiar with archaeobotany but not enough for an ethnobiologist or reader unfamiliar with archaeological practices. Consequently, both too much and too little space is spent on background information which breaks up the flow of the discussion and leads to repetitious writing. Additional site photographs, building plans, and seed and charcoal images would have benefited all readers. Moreover, while the use of theory is integral to archaeology, the conclusions drawn from the data did not, in this reviewer's opinion, require the complicated theoretical frameworks presented in chapter 2. Instead, it would have been more valuable to see the integration of other forms of material culture from the site, such as ceramics, and a more lengthy discussion of the role and interaction of Gordion with broader cultural and political trends taking place in ancient Anatolia and the wider Mediterranean. Although the book focuses on human decision making, the intense focus on the environmental data, revealing changes that happened over several centuries, leaves the reader feeling detached from the site and its inhabitants. It is only in the concluding chapter that Gordion is finally put 
back into its broader social framework. Despite these drawbacks, the volume is a good demonstration of how environmental archaeology and archaeobotany is moving beyond the simple taxa list and a powerful reminder that neither climate nor culture can ever be factored out of a discussion on human decision making, past or present.

\section{References Cited}

Marston, J. 2010. Evaluating Risk, Sustainability, and Decision Making in Agricultural and Land-Use Strategies at Ancient Gordion. Unpublished Doctoral Dissertation, Interdepartmental Graduate Program in Archaeology, University of California, Los Angeles, CA.

Marston, J., and N. Miller. 2014. Intensive Agriculture and Land Use at Roman Gordion, Central Turkey. Vegetation History and Archaeobotany 23:761-773. DOI:10.1007/s00334-014-0467-x.
Veal, R. 2009. The Wood Fuel Supply to Pompeii: An Environmental, Historical and Economic Study: $3^{\text {rd }}$ c. $\mathrm{BC}$ to $\mathrm{AD}$ 79. Unpublished Doctoral Dissertation, Department of Archaeology, University of Sydney, Sydney, Australia.

Veal, R. 2012. From Context to Economy: Charcoal as an Archaeological Interpretive Tool, A Case Study from Pompeii $3^{\text {rd }}$ c. BC to AD 79. In More than Just Numbers? The Role of Science in Roman Archaeology, Journal of Roman Archaeology Supplement No. 91, edited by I. E. Schrüfer-Kolb, pp 19-52. Portsmouth, RI. 